\title{
Mixed Layer formation and restratification in presence of mesoscale and submesoscale turbulence
}

\author{
Couvelard Xavier ${ }^{2}$, Dumas Franck ${ }^{2}$, Garnier Valerie ${ }^{2}$, Ponte Aurelien ${ }^{3}$, Talandier Claude ${ }^{1}$, \\ Treguier Anne-Marie ${ }^{1}$
}

${ }^{1}$ CNRS, Laboratoire de Physique des Océans, UMR 6523 CNRS-Ifremer-IRD-UBO, Centre Ifremer de Brest, Plouzané, FRANCE

${ }_{2}^{2}$ Ifremer, DYNECO-PHYSED/IFREMER, Centre Ifremer de Brest, Plouzané, FRANCE

${ }^{3}$ CNRS, Laboratoire de Physique des Océans, UMR 6523 CNRS-Ifremer-IRD-UBO, Centre Ifremer de Brest, Plouzané, FRANCE

* Corresponding author: Xavier Couvelard, Tel.: +33665395734. ;

email address : xaviercouvelard@gmail.com

\begin{abstract}
:
Recent realistic high resolution modeling studies show a net increase of submesoscale activity in fall and winter when the mixed layer depth is at its maximum. This submesoscale activity increase is associated with a reduced deepening of the mixed layer. Both phenomena can be related to the development of mixed layer instabilities, which convert available potential energy into submesoscale eddy kinetic energy and contribute to a fast restratification by slumping the horizontal density gradient in the mixed layer. In the present work, the mixed layer formation and restratification was studied by uniformly cooling a fully turbulent zonal jet in a periodic channel at different resolutions, from eddy resolving $(10 \mathrm{~km})$ to submesoscale permitting $(2 \mathrm{~km})$. The effect of the submesoscale activity, highlighted by these different horizontal resolutions, was quantified in terms of mixed layer depth, restratification rate and buoyancy fluxes. Contrary to many idealized studies focusing on the restratification phase only, this study addresses a continuous event of mixed layer formation followed by its complete restratification. The robustness of the present results was established by ensemble simulations. The results show that, at higher resolution, when submesoscale starts to be resolved, the mixed layer formed during the surface cooling is significantly shallower and the total restratification almost three times faster. Such differences between coarse and fine resolution models are consistent with the submesoscale upward buoyancy flux, which balances the convection during the formation phase and accelerates the restratification once the surface cooling is stopped. This submesoscale buoyancy flux is active even below the mixed layer. Our simulations show that mesoscale dynamics also cause restratification, but on longer time scales. Finally, the spatial distribution of the mixed layer depth is highly heterogeneous in the presence of submesoscale activity, prompting the question of whether it is possible to parameterize submesoscale effects and their effects on the marine biology as a function of a spatially-averaged mixed layer depth.
\end{abstract}




\section{Highlights}

- Mixed Layer formation and restratification is studied by cooling a tubulent jet. $>$ Submesoscale activity balances the convection and reduces the mixed layer depth. Restratification efficiency is increased when submesoscale is resolved. The Mixed layer depth become spatially heterogeneous when submesoscale is active. The spatial distribution of the mixed layer depth is shown to flaten with time.

Keywords : Baroclinic Jet, Mixed Layer Instabilities, Restratification, Mixed Layer Depth, vertical mixing, NEMO 


\section{Introduction}


A correct representation of the mixed layer depth (MLD) in a numerical model is a priority when considering ocean heat content and heat exchange between ocean and atmosphere, either for the climate (Romanou et al., 2013; Sallee et al., 2013; Liu and Wang, 2014) or in the case of tropical cyclones (Lin et al., 2009; Shay and Brewster, 2010; Seo and Xie, 2013). As resolving the submesoscale is beyond the scope of current climate, global and some regional models, Fox-Kemper et al. (2008) proposed a parameterization of the restratification induced by MLIs in coarse resolution models, which consists of an overturning streamfunction confined to the mixed layer and proportional to the strength of the horizontal surface density gradient and the MLD. In a companion paper, Fox-Kemper and Ferrari (2008) show that the equivalent MLI heat fluxes estimated from observed surface eddy kinetic energy using the Fox-Kemper et al. (2008) parameterization are of the same order of magnitude as the atmospheric flux, suggesting that restratification by MLIs could be a leading order process for the mixed layer.

The predominance of MLIs for the submesoscale dynamics of the mixed layer has been confirmed by recent realistic high resolution modeling studies from Capet et al. (2008d), Mensa et al. (2013) and Sasaki et al. (2014), showing a net increase of submesoscale activity in fall and winter associated with the deepest mixed layers. Such a seasonality in the submesoscale field has recently been confirmed from observations by Callies et al. (2015). While Capet et al. (2008d) could not see any submesoscale-induced restratification in the shallow domain of the Argentinian shelf, Mensa et al. (2013) found a mixed layer $25 \%$ shallower in a submesoscale permitting high resolution nested domain $(\sim 2 \mathrm{~km})$ compared to its parent eddy resolving $(\sim 8.5 \mathrm{~km})$ model of the Gulf Stream area. Since mesoscale fronts are present all year long in this region Mensa et al. (2013) concluded that this fall/winter APE increase available to MLIs is controlled by the MLD. Shallowing of the mixed hayer by MLIs is also reported by Marchesiello et al. (2011) in their numerical study of tropical instability waves when the submesoscale is resolved.

Among the studies cited above there exists a significant gap between simulations using realistic coastline and topography and highly idealized ones, most of those latter being initialized with a preexisting mixed layer and front. Furthermore, results from idealized experiments are not in full agreement with each other. For instance Fox-Kemper et al. (2008) noted that vertical heat fluxes from MLIs are small compared to ocean-atmosphere heat fluxes during active convection periods, while Haine and Marshall (1998) previously showed that MLIs can be active during convective process and even overtake them. It has been also shown 
by Taylor and Ferrari (2010) that in the early stage of the mixed layer formation, Symmetric Instability (SI) can limit the deepening of the mixed layer. They also highlight that such SI will arise when the Richardson number is beyond unity.

Furthermore, while idealized studies focus on a single realization of a restratification event, studies based on realistic models focus on averaged MLD resulting from various atmospheric events. Moreover, it has been demonstrated that oceanic convection due to atmospheric cooling is preconditioned by the mesoscale activity (Legg et al., 1998), suggesting that ensemble simulations are needed to robustly investigate the effect of MLIs on the MLD.

In the present work we use an idealized domain wide enough to allow fully deyéloped mesoscale dynamics and fine enough to permit submesoscale dynamics produced by destabilization of mesoscale fronts, and we focus on the effect of the submesoscale on a single mixed layer formation and restratification cycle forced by a buoyancy flux. We aim to address the following questions: (i) Are MLIs able to counter balance the convection during mixed layer formation? (ii) How much do they speed up the restratification once convection is stopped? For statistical reliability of the results, the analyses were based on ensemble simulations.

The paper is organized as follows: section 2 covers the modeling setup, describing the ensemble simulations and diagnostics used; section 3 presents results for a reference simulation and for the different resolutions; the findings are then discussed in section 4.

\section{Methods - Modeling setup}

Mixed layer formation and restratification was studied by cooling a turbulent zonal jet in a periodic channel. The impact of the submesoscale dynamics is highlighted through the comparison of different horizontal resolutions either allowing submesoscale activity $(2 \mathrm{~km})$ or not $(10 \mathrm{~km})$, plus an intermediate resolution $(5 \mathrm{~km})$ and is quantified through MLD, restratification rate, buoyancy fluxes, and conversion of available potential energy into eddy kinetic energy.

\subsection{The numerical model}

We use the numerical NEMO model (Madec, 2008), which solves the three-dimensional primitive equations in spherical coordinates discretized on an Arakawa C-grid. Aiming to keep the configuration as simple 
as possible, the vertical mixing coefficients are set constant with values of $1.2 \cdot 10^{-4}$ and $1.2 \cdot 10^{-5} \mathrm{~m}^{2} \mathrm{~s}^{-1}$ for momentum and tracers respectively and the convective processes are mimicked using an enhanced vertical diffusion parameterization which increases vertical momentum viscosity and tracers diffusity to $100 \mathrm{~m}^{2} \mathrm{~s}^{-1}$, where static instability occurs. This setup is similar to the configuration of Boccaletti et al. (2007). In our study, as the mixed layer is forced exclusively by a surface buoyancy flux generating static instabilities, the use of the enhanced vertical diffusion with constant background mixing coefficients instead of a turbulent closure such as TKE (Turbulent Kinetic Energy) or k- $\epsilon$ seems appropriate. This was confirmed by experiments made with TKE instead of the constant background diffusivity (not shown), which do not display large qualitative differences. The linear equation of state depends on temperature only and the model is set up with a $z$ vertical coordinate and a linearized free-surface formulation (Roullet and Madec, 2000). A third order upwind biased (UBS) advection scheme, for which diffusivity is equal (in a one dimensional advection problem) to $\frac{1}{12}|U| \Delta x^{3}$, where $|U|$ is the absolute local velocity and $\Delta x$ the grid spacing (Marchesiello et al., 2009), is used for both momentum and tracers. It has been recently shown by Mohammadi-Aragh et al. (2015) that the spurious diapycnal mixing induced by such diffusive schemes during the restratification phase of a baroclinic instability, can lead to some change in the background potential energy. In the present study, the sensitivity to the choice of advection scheme is not considered, as we focus on the effect of spatial resolution.

\subsection{The baroclinic jet}

The Antarctic Circumpolar Current (ACC) has been often idealized as a zonally symmetric baroclinic jet (McWilliams and Chow, 1981; Klein et al., 2008, 2011) to study the generation of baroclinic instability and associated mesoscale and submesoscale dynamics. This idealized baroclinic jet (hereafter refereed as BJET) is simulated in a $2000 \mathrm{~km}$ (North-South) * $500 \mathrm{~km}$ (East-West) domain with a $4000 \mathrm{~m}$ deep flat bottom on a beta plane $\left(f=5.57 \cdot 10^{-5} \mathrm{~s}^{-1}, \beta=2 \cdot 10^{-11} \mathrm{~s}^{-1} \mathrm{~m}^{-1}\right)$. The domain is periodic in the zonal direction (a zonal reentrant channel) and a free slip lateral boundary condition is applied to the north and south vertical walls. A linear bottom friction relation is used with a coefficient $r=5 \cdot 10^{-3} \mathrm{~m}^{2} \mathrm{~s}^{-1}$. All configurations are built using 100 vertical levels keeping an almost constant spacing of $5 \mathrm{~m}$ over the first $200 \mathrm{~m}$ of the water column and increasing further down to a maximum layer thickness of $90 \mathrm{~m}$. Initial zonal velocities (Figure 1) are in geostrophic balance and the jet destabilization is triggered by a very small random density perturbation. 
The flow is maintained by nudging of the zonally-averaged velocity and density fields towards the initial state (without the perturbation), with a time scale of 50 days. The first baroclinic Rossby deformation radius varies from $17 \mathrm{~km}$ to $37 \mathrm{~km}$ from the south to the north $(25 \mathrm{~km}$ in the middle of the jet). A full description of the initial baroclinic jet is given in the appendix.

\subsection{The cooling event}

To form the mixed layer of the BJET simulation (cf 2.2), the nudging is stopped and a net surface heat flux of $300 \mathrm{Wm}^{-2}$ is uniformly applied over the baroclinic jet for a 20 day period. This net heat flux is typical of winter conditions obtained from observations of the North Atlantic (Lavender and Davis, 2002; Straneo, 2005) and in the range of the values used by Haine and Marshall (1998). With such a heat flux, 20 days are enough to form a mixed layer a few hundred meters deep. After 20 days, the heat flux is turned off and the model runs freely (with nudging still off) for another 60 days, making it possible to study the restratification phase. The nudging had to be turned off-during the convection phase, because it would otherwise strongly interact with the mixed layer deepening. The time scale of the experiments ( 80 days) is small compared with the spin-down time of the unforced jet; this was verified by running some simulations (not shown) without cooling or nudging, showing that the BJET does not lose significant kinetic energy in 80 days. To account for the full mixed layer formation/restratification cycle, the 20 days prior to the cooling were extracted and considered in the analyses (for those first 20 days when nudging was applied). Figure 2 provides a schematic view of the cooling event by representing the time series of the MLD determined using a density based criterion, i.e., $\rho(z)-\rho($ surface $)<0.03 \mathrm{~kg} \cdot \mathrm{m}^{-3}$ (de Boyer Montégut et al., 2004), contrasting the eddying simulations (blue curves) with the case of a zonal jet without eddies (black curve). Before the onset of the cooling the mixed layer represented in Figure 2 is not an actual mixed layer but simply an arbitrary depth picked up by the density criterion used.

\subsection{Description of the ensembles}

Preliminary experiments have shown that, depending on the starting date of the cooling event, substantial differences in MLD can be observed. To overcome this variability and to be able to establish robust comparisons between the different experiments, ensemble simulations were performed for each resolution. The shaded area in Figure 2 represents the spread of the MLD obtained from the different realizations of 
the cooling event. MLD differences of almost $40 \mathrm{~m}$ can be found, which represent a variability of the order of $20 \%$.

Ensembles were realized as follows: a 4 year-long simulation of BJET is run ( 3 years only at $2 \mathrm{~km}$ due to the computational cost). The first year is removed as it includes the spin-up time. After the first year, a restart file is saved every 3 months and used as the initial condition for the cooling event for one ensemble member. Each member is composed of 100 mean daily outputs, where cooling is applied between days 20 and 40 as described in Figure 2. Eddy fields at 3 month intervals are not strongly correlated: surface velocities, surface density anomaly, and sea surface height anomaly between two subsequent restarts (90 days) show a maximum correlation of the order of 10 to $30 \%$. Our ensemble averages (using 12 members at 5 and $10 \mathrm{~km}$ resolution, and 8 members at $2 \mathrm{~km}$ ) are thus statistically significant, allowing robust comparisons of the simulations at different spatial resolutions.

\subsection{Reference simulation}

To provide a first description of the dynamics of the cooling experiment, we make a detailed presentation of a single member obtained at $2 \mathrm{~km}$ resolution. This single simulation is hereafter referred as the reference simulation. To restrain the study to the most turbulent area, the MLD calculation and the following analyses were performed over a box which has $400 \mathrm{~km}$ meridional extension centered in the middle of the jet but extends all along the zonal extent of the domain (i.e., $400 \mathrm{~km} * 500 \mathrm{~km}$, thick black line in Figure 1b). Some tests (not shown) were performed with larger and smaller meridional extents, without any qualitative change of the results.

Although the spatially-averaged MLD was considered in the analyses and comparisons, it is important to keep in mind that in such a turbulent flow eddies induce a very high spatial variability of the MLD, which can vary from $50 \mathrm{~m}$ to more than $300 \mathrm{~m}$ as shown in Figure 3 but which leads to a spatially-averaged MLD of $\mathrm{O}(200 \mathrm{~m})$ (Figure 2). All the following analyses were made through the use of mean daily model outputs.

\subsection{Scale separation}

It is useful to separate the mesoscale and large scale from the submesoscale part of the flow field. This makes it possible to isolate the effect of submesoscale and large scale on the mixed layer formation and restratification. For this purpose we used a spatio-temporal low pass filter (Capet et al., 2008a; Marchesiello 
et al., 2011) removing any spatial scales greater than $40 \mathrm{~km}$ (twice the minimum Rd inside the jet) and 3 days. Any variable $v$ can therefore be decomposed as follows: $v=v^{\prime}+v^{\prime \prime}$. Here, we keep the formalism used by Capet et al. (2008a), except that $v^{\prime}$ represents the averaged plus mesoscale component of the flow. $v^{\prime \prime}$ corresponds to the submesoscale component.

Figure 4 shows the two components of the velocity field: i.e., from left to right, the total velocity, the low pass filtered variable and the residual (submesoscale), for surface velocities extracted from BJET. Although submesoscale eddies are more intense along mesoscale structures, as also pointed out by Fox-Kemper et al. (2008); Capet et al. (2008a) and Mensa et al. (2013), they are present almost everywhere. Note that Figure 4 shows the meridional extent of the turbulent zone, justifying the closed north and south boundaries, since turbulence is almost totally absent $400 \mathrm{~km}$ from the boundary.

\section{Results}

\subsection{Surface vorticity and kinetic energy of the reference simulation}

Figure 5 shows maps of the vertical component of relative surface vorticity $(\zeta=\vec{\nabla} \times \vec{u} \cdot \vec{k})$ just before (day 19), during (day 35), and following (days 45 and 90) the cooling event. Once the mixed layer is formed, and during the first days of the restratification, a large increase of the variance of $\zeta$ can be observed.This is characterized by the emergence of smaller scales along the edges of mesoscale eddies and filaments. At day 90, the small scales have disappeared but, as shown in Figure 6, which represents the evolution of RMS $\zeta$ with time, the RMS $\zeta$ increases by $23 \%$ between day 19 and day 90 . Following Boccaletti et al. (2007), this net $\zeta$ increase at small scale could be consistent with the development of MLIs, which release submesoscale eddy kinetic energy (EKE) extracted from available potential energy (APE) by slumping of the isopycnals. Part of the submesoscale energy would be then transferred to mesoscale through an inverse cascade and part/of it would be dissipated by the diffusive advection scheme (Mohammadi-Aragh et al., 2015) and the temporal Assellin filter (Soufflet et al., 2015; Lemarie et al., 2015) used in NEMO, resulting in the mésoscale eddy field observed at day 90. Indeed, Figure 7, which represents the kinetic energy spectra, computed along the zonal direction and averaged meridionaly over the middle box for each panel of Figure 5 shows an increase of kinetic energy at all scales for days 35 and 45 which could be due to the APE-EKE conversion and an associated inverse cascade. At day 35 (after 15 days of cooling, red spectra), 
the energy is increased at scales between 9 and $300 \mathrm{~km}$. At day 45 (5 days after the end of the cooling, green spectra), the energy keep increasing up to scale of $800 \mathrm{~km}$. This increase of energy at large scale between day 35 and 45 seems representative of an inverse cascade. After restratification (day 90 - black spectra), while the energy level at small scales is dissipated and identical to the level of day 19 (blue spectra), the increased kinetic energy at large scale is still well marked, confirming the visual impression from Figure 5. This is also consistent with the seasonal spectrum made by Sasaki et al. (2014).

\subsection{Mixed layer formation and restratification in the reference simulation}

The spatially-averaged MLD during the experiment is shown in Figure 2. The blue line represents the mean MLD (average among all the members) and the shaded area its yariability among the ensemble. At day 20, when the cooling is applied a fast deepening of the MLD is observed during the first 7-8 days. Then the mixed layer stabilizes its depth while surface cooling is still applied. When the cooling experiment is reproduced over a laminar jet, i.e over a jet having the same initial condition than the baroclinic jet (described in 2.2) but where the baroclinic instability is not seeded by the perturbation, the mixed layer continues to deepen with time (cf. Figure 2, black line). The arrest of the mixed layer deepening is therefore associated with the turbulent dynamics of the jet, especially its submesoscale component, as we demonstrate in the following analysis.

Figure 8 shows the surface density and the associated submesoscale component of the vertical buoyancy fluxes at $100 \mathrm{~m}$ depth before and during the mixed layer formation. Figures 8 (b) and (d) are taken after 15 days of cooling (day 35) when the mixed layer has already ceased its deepening. While in the absence of a mixed layer we find submesoscale $w^{\prime \prime} b^{\prime \prime}$ patterns following mesoscale fronts (panel (a) and (b)), at day 35 , as a result of the fully developed MLIs, $w^{\prime \prime} b^{\prime \prime}$ develops everywhere where there is spatial variability due to the variance of the density fronts at submesoscale. Furthermore, a spatial average of $w^{\prime \prime} b^{\prime \prime}$ indicates an increase by a factor of 30 compared with the initial condition. This submesoscale increase is also clearly noticeable on the surface density in Figure $8 \mathrm{~b}$ where the smooth fronts of Figure 8a are ubiquitously disrupted by small scales structures. A snapshot of the surface density at day 35 for a simulation made without cooling (not shown) exhibits very smooth mesoscale fronts, confirming that even for small time scale (few days) the emergence of submesoscale is directly linked with the generation of the mixed layer (and not with the fact that we switched off the nudging before we started the cooling). This result seems to be in 
agreement with Capet et al. (2008d), Mensa et al. (2013) and Sasaki et al. (2014), who already highlighted the link between MLD and submesoscale activity at the seasonal scale. This increase of the buoyancy flux by submesoscale dynamics is, therefore, believed to be responsible for the arrest of the convection and the deepening of the mixed layer as shown in Figures 2 and 9, and confirms previous results obtained by Haine and Marshall (1998).

Although Brannigan et al. (2015) show in their simulation that a significant proportion of the mixed layer can be favorable to Symmetric Instability, the Richardson number $R i=\frac{N^{2}}{\left(\frac{\partial U \mid}{\partial z}\right)^{2}}$ during the cooling event is comprise in the range [10 800] $80 \%$ of the time, with a median value of 64 , only $6 \%$ inferior to 10 and $0.01 \%$ inferior to one. It is therefore very unlikely, although the Ertel potential vorticity being negative in the mixed layer during the cooling phase, that any SI nor hybrid symmetric-baroclinic instability would exist in our configuration, even in the early stage of the cooling before the MLIs get finite amplitude.

At day 40, when the surface heat flux is stopped, the competition between convection and submesoscale vertical buoyancy flux stops, leading to the fast restratification observed in our simulation.

This hypothesis tends to be confirmed by the vertical structure of the vertical buoyancy flux. A timedepth plot of the horizontally-averaged vertical profile of the first $350 \mathrm{~m}$ has been built for $\left\langle w^{\prime} b^{\prime}\right\rangle$ and $\left\langle w^{\prime \prime} b^{\prime \prime}\right\rangle$ (Figure 9, panel (a) and (b) respectively) where \langle\rangle denotes a horizontal average. The overlaid dark line represents the horizontally-averaged MLD. While no obvious link can be seen between $\left\langle w^{\prime} b^{\prime}\right\rangle$ and the MLD, $\left\langle w^{\prime \prime} b^{\prime \prime}\right\rangle$ is highly correlated with the MLD and at least an order of magnitude greater than $\left\langle w^{\prime} b^{\prime}\right\rangle$. Indeed this Figure suggests that the mixed layer deepening is stopped when $\left\langle w^{\prime \prime} b^{\prime \prime}\right\rangle$ starts to be significant, while $\left\langle w^{\prime \prime} b^{\prime \prime}\right\rangle$ only vanishes after the restratification is completed.

The penetration of $\left\langle w^{\prime \prime} b^{\prime \prime}\right\rangle$ under the mixed layer can be explained by many factors. As shown in Figure 3, and later in Figure 13, the MLD is highly heterogeneous, allowing locally a deep (up to $400 \mathrm{~m}$ ) penetration of $\left\langle w^{\prime \prime} b^{\prime \prime}\right\rangle$. Nevertheless it seems unlikely that $\left\langle w^{\prime \prime} b^{\prime \prime}\right\rangle$ would not be contained inside the mixed layer in the spatial average. Another explanation could be the penetration of $\left\langle w^{\prime \prime} b^{\prime \prime}\right\rangle$ under the mixed layer due to weak stratification at its base. Indeed, Figure 9(c) representing the spatially averaged BruntVasaila frequency $\left(\mathrm{N}^{2}\right)$ shows that low values of $\mathrm{N}^{2}$ can be found under the MLD determined by the density criterion. Furthermore, a low stratification layer persists for a few days after the restratification. This might explain the deep persisting $<w^{\prime \prime} b^{\prime \prime}>$ under the mixed layer after restratification seen in Figure 9(b). This 
deep $<w^{\prime \prime} b^{\prime \prime}>$ could also result from interactions between the submesoscale activity inside the mixed layer and mesoscale activity under the mixed layer, as shown by Ramachandran et al. (2014).

The vertically-averaged (over $350 \mathrm{~m}$ ) vertical mesoscale and submesoscale buoyancy fluxes, which are equivalent to the conversion term between APE and KE (Capet et al., 2008d; Fox-Kemper et al., 2008; Mensa et al., 2013), are represented in Figure 10, converted into the equivalent amount of heat flux Q necessary to change the equivalent amount of buoyancy $\left(Q=C_{p} \rho \overline{w^{\prime} b^{\prime}} / g \alpha_{T}\right)$ as in Boccaletti et al. (2007) and Fox-Kemper and Ferrari (2008). It has to be noted that we did not use the MLD as determined by the density criterion, but an arbitrary depth of $350 \mathrm{~m}$ which encompasses all the vertical buoyancy flux induced by the cooling. Figure 10 shows that the submesoscale flux represents up to $85 \%$ of the total flux when at its maximum (day 40). It is also interesting to note that while the submesoscale vertical buoyancy flux keeps increasing during the whole cooling event, the MLD stays almost constant. The MLD stops deepening around 30 days (Figure 2) when the vertically-averaged $\left\langle w^{\prime \prime} b^{\prime \prime}\right\rangle$ reaches $50 \mathrm{~W} \cdot \mathrm{m}^{-2}$, which is only $16 \%$ of the surface heat flux $\left(300 \mathrm{~W} \cdot \mathrm{m}^{-2}\right)$.

\subsection{Sensitivity to the horizontal resolution}

The horizontally-averaged MLD for the different resolutions is represented in Figure 11a (symbols) overlaid with the MLD obtained for a laminar jet (black line). All curves represent the average of each ensemble while the shaded area represents the envelope of each ensemble. At $10 \mathrm{~km}$, the MLD reached after 20 days of surface cooling corresponds to the unperturbed MLD suggesting there is no influence of the submesoscale dynamics on the formation of the mixed layer as expected at such resolution since submesoscale cannot yet be resolved. At $5 \mathrm{~km}$, although an arrest in the deepening of the mixed layer is unclear, a slowing in the rate of deepening is well marked leading to a mixed layer $25 \mathrm{~m}$ shallower than at $10 \mathrm{~km}$. At $2 \mathrm{~km}$, we can observe the full arrest previously described above and a mixed layer more than 100 $\mathrm{m}$ shallower than without turbulence.

Once the surface cooling has stopped, a clear increase in the restratification rate can also be noticed (Figure 11a), being faster with the increased resolution, supporting the importance of submesoscale dynamics in the restratification phase. The resolution dependence during the mixed layer formation and restratification is consistent with the upward submesoscale buoyancy fluxes. The spatially- and vertically- (over 350 m) averaged submesoscale buoyancy flux (Figure 11b) shows large differences between the 3 resolutions. 
Although the density-based criterion used to define the MLD indicates a mixed layer shallower than $350 \mathrm{~m}$, it is clear from comparison with other experiments that all the vertical buoyancy flux is associated with the formation of the mixed layer. Therefore by averaging vertically between 0 and $350 \mathrm{~m}$ all the variability is included. At $2 \mathrm{~km}$ resolution (red line) the flux is stronger but also starts to increase earlier than at other resolutions, explaining the earlier arrest of the mixed layer deepening, while the increase starts later and with a smaller amplitude at $5 \mathrm{~km}$ and is completely absent at $10 \mathrm{~km}$. At $10 \mathrm{~km}$ resolution, the submesoscale buoyancy flux is negligible during the cooling period.

The spread of the evolution of the MLD over the ensemble at each resolution (shaded area of Figure 11a) is an interesting result. No variability can be seen during the convective phase at any of the resolutions, all simulations displaying the exact same rate of deepening following the one of the laminar jet. Nevertheless, when focusing on the stabilization of the mixed layer depth and the following restratification phase, large differences can be seen. At $10 \mathrm{~km}$, there is no variability of the MLD during the cooling phase but a wide spread of the solution during the restratification. At $5 \mathrm{~km}$, the spread is reduced during the restratification phase, but there is also some variability among ensemble members during the cooling phase, while at $2 \mathrm{~km}$ there is almost no variability during the restratification phase but an important variability of the MLD during the cooling phase.

One remaining question concerns the convergence of our solutions in term of horizontal resolution. Figure 12 shows the maximum values of large scale and submesoscale vertically-averaged vertical buoyancy fluxes and their spread among the ensembles. Figure $11 \mathrm{~b}$ suggests that the maximum is relevant enough to compare the different resolutions in terms of vertically-averaged vertical buoyancy fluxes. Although the large scale flux tends to be independent of the resolution, being slightly more important at $10 \mathrm{~km}$ but almost equal at 5 and $2 \mathrm{~km}$, a quasi-linear growth of the submesoscale component with the increase of the resolution can be observed, suggesting that higher horizontal resolution is needed to test the convergence of our solutions.

\subsection{Sensitivity to initial conditions}

To confirm that the differences in the MLD among the different resolutions are not linked to the different initial conditions, three different experiments were designed. Firstly the initial condition for one of the members at $2 \mathrm{~km}$ was submitted to the cooling at each grid point independently, using a 1D-vertical 
configuration of the NEMO model. The spatially-averaged MLD obtained was similar to the one obtain at $10 \mathrm{~km}$ and with the laminar jet. Secondly, the same initial condition was interpolated on the $10 \mathrm{~km}$ grid and the cooling experiment reproduced, resulting in a solution similar to the one obtained with the experiments made at $10 \mathrm{~km}$. Thirdly a simulation at $2 \mathrm{~km}$ resolution was re-run with its initial condition at $2 \mathrm{~km}$, but with this initial condition smoothed (using the filter described in 2.6) to resemble the $10 \mathrm{~km}$ initial condition. After cooling, we obtained an arrest of the mixed layer deepening equivalent to the one obtained with the other ensemble experiments made at $2 \mathrm{~km}$. These three sensitivity experiments demonstrate the independence of our findings with respect to the initial condition. They confirm that when submesoscales start to be resolved, this can counterbalance the vertical mixing regardless of the presence of submesoscales in the initial condition.

\section{Discussions and Conclusion}

In this paper, the competition between convective mixing due to surface cooling and the three-dimensional dynamics of the mixed layer was studied in an idéalized baroclinic jet. Unlike idealized studies such as Boccaletti et al. (2007), the configuration covers a large domain allowing for submesoscale production by destabilization of mesoscale meanders and eddies into submesoscale eddies and filaments. We have shown that, when permitted (i.e., $2 \mathrm{~km}$ resolution in our case) submesoscale dynamics are able to counter balance the vertical mixing, inhibiting the deepening of the MLD.

In the reference simulation the submesoscale variance of the density gradients and the buoyancy fluxes are considerably increased in the presence of a deep mixed layer, due to APE-EKE conversion by MLIs following previous results of Capet et al. (2008d), Mensa et al. (2013) and Sasaki et al. (2014). While Fox-Kemper et al. (2008) noted that during active convection the effect of MLIs should be secondary, the restratification induced by MLIs in our reference simulation leads to an arrest of the mixed layer deepening at two thirds of the MLD obtained in absence of turbulence, in agreement with previous results from Haine and Marshall (1998).

In their realistic configuration, Mensa et al. (2013) observe a reduction of $25 \%$ of the MLD when increasing the resolution. The reduction of the bias with climatology in a global model, when using the Fox-Kemper et al. (2008) parameterization, can be roughly estimated to be $10 \%$ from Fox-Kemper et al. 
(2011). In our experiments, MLD is found to be reduced from $29 \%$ up to $40 \%$ (compared to the MLD obtained for the laminar jet). This variability in MLD between members of our ensemble simulations is not clearly linked to the initial eddy kinetic energy or $\zeta$, although it is necessarily related to the initial mesoscale field present at the beginning of the cooling phase for each ensemble member. Moreover, this suggests that in realistic simulations MLIs might not only reduce the averaged MLD but also increase the temporal variability of the spatially-averaged MLD. Indeed in our lower resolution experiment $(10 \mathrm{~km})$, almost no MLD variability can be seen between the different members while at $5 \mathrm{~km}$ the shallowing of the mixed layer is between $8 \%$ and $19 \%$ (compared with the laminar jet case). Since there is no seasonal cycle in our simulations, this observed variability results directly from the submesoscale dynamics.

Besides the variability of the spatially-averaged MLD, a close look at the spatial organization of the MLD in the reference simulation (or any other member) shows that the MLD is highly heterogeneous and that its distribution evolves with time. While the spatially-averaged MLD remains almost constant over the last 10 days of the cooling event, the MLD distribution keeps evolving, increasing both its skewness and kurtosis. As shown in Figure 13a between days 23 and 27, the mixed layer becomes increasingly deep on average and the MLD becomes increasingly heterogeneous. Once the MLIs become active at day 31, and the average MLD stops increasing, the number of occurrences of both deep and shallow MLDs continues to increase such that the average stays constant. While the cooling keeps being applied the MLD continues to take extreme values, i.e., deeper MLD are seen with time but also are shallower MLD, leading to a constant MLD when spatially-averaged. In comparison the evolution of the spatial distribution of the MLD obtained at $10 \mathrm{~km}$ (Figure 13b) is completely different. At this resolution, the distribution is constantly shifted to deeper values while its shape does not evolve much with time. Two maps of the MLD at $2 \mathrm{~km}$ and $10 \mathrm{~km}$ resolutions, taken after 10 days of cooling, illustrate the spatial distribution. While Figure $13 \mathrm{c}(2 \mathrm{~km})$ reveals strong gradients and heterogeneity in the MLD, Figure $13 \mathrm{~d}(10 \mathrm{~km})$ shows very smooth spatial differences in MLD corresponding to a more classical view of the mixed layer. The MLD obtained at $2 \mathrm{~km}$ raises the question of the physical meaning of an averaged MLD in high resolution models and its more general physical meaning in areas of intense submesoscale activity.

The restratification rate, except for the highly idealized Boccaletti et al. (2007) and the subsequent Fox-Kemper et al. (2008) parameterization, has not been quantified in previous studies. Fox-Kemper et al. 
(2011); Marchesiello et al. (2011); Mensa et al. (2013) found a reduction of the MLD when resolving submesoscale or when using Fox-Kemper et al. (2008) parameterization, but our experiments at different resolutions also show large differences in the time over which restratification occurs after the surface heat flux is stopped. Indeed total restratification takes more than 40 days at $10 \mathrm{~km}, 20$ days at $5 \mathrm{~km}$, and less than 10 days at $2 \mathrm{~km}$ resolution (Figure 11) with an averaged MLD shallowing rate estimated at 7 , 13 and $17 \mathrm{~m}$ per day, respectively. A correct representation of the restratification can strongly influence the biology of plankton, which develops on time scales of the order of a day. Recent studies (Taylor and Ferrari, 2011; Mahadevan et al., 2012; Swart et al., 2014) have shown that, in frontal zones, restratification by MLIs reduces the turbulent flux of phytoplankton out of the euphotic zone, thereby increasing its mean light exposure (Taylor and Ferrari, 2011). By potentially bringing nutrients into the mixed layer (Swart et al., 2014), submesoscale vertical buoyancy fluxes could allow an earlier phytoplankton spring bloom. Taylor and Ferrari (2011) conjecture that the increase of primary production induced by such an earlier start of spring bloom at high latitude fronts likely increases the ocean uptake of carbon dioxide and plays an important role in the global carbon cycle.

In the absence of slumping of isopycnals by MLIs (as would be the case in our experiments at $10 \mathrm{~km}$ resolution), the simulated bloom only appears after the restratification is made by surface heat fluxes, inducing a delay up to 30 days in the emergence of the bloom (Mahadevan et al., 2012). This 30 day delay is also seen in our simulations between the $2 \mathrm{~km}$ and $10 \mathrm{~km}$ experiments considering the mixed layer restratification, so we would expect the same 30 day delay in the emergence of a bloom if we had a biogeochemical model plugged into our model. Note that our experiments suggest that a slow but complete restratification can be performed by the mesoscale eddies only, even in the absence of any surface heating. Our simulations confirm that accurate representation of the mixed layer depth and its restratification rate, and therefore of the submesoscale dynamics, is needed in biochemical modeling studies. This confirms the benefits of the grid coarsening method as proposed by Lévy et al. (2012) or the benefit of accurate MLI parameterization (Fox-Kemper et al., 2008). We suggest that the relevance of such parameterization should be tested systematically during cooling phases, where the competition between surface-cooling-induced convection and submesoscale-induced restratification leads to a stabilization of the MLD and, therefore, controls the depth from which nutrients can be pulled into the mixed layer. 
Although the parameterization of the vertical mixing is very similar to what is classically used in NEMO, a generalization of these results could be made using other schemes such as k- $\epsilon$, KPP, or GLS. Higher resolution would also be needed, by allowing to properly resolve SI at the early stage of the mixed layer formation (Hamlington et al., 2014; Brannigan et al., 2015), but also resolve the forward cascade of energy (Skyllingstad and Samelson, 2012)

In our model simulations, only the influence of cooling was considered. Interactions between convection, MLIs and vertical mixing of momentum induced by wind forcing should also be investigated. The effect of surface waves and Langmuir cells should also be considered as they might change the results presented here by introducing more vertical mixing. Hamlington et al. (2014) show for instance that in a mixed layer favorable to restratification by SI, the MLD can be twice as deep when Langmuir turbulence is included. While they focus on the case of a mixed layer spindown, the effect of Langmuir turbulence should be tested during the formation of a deep mixed layer subject to MLIs

\section{Appendix}

The initial density field is constructed as follows: a dense and a light profile $\rho_{N}(z)$ and $\rho_{S}(z)$ are defined that are made of 4 components: (1) a small depth-independent background stratification that applies equally to the northern and southern profiles and guarantees static stability; (2) an exponential density profile, which enhances near-surface stratification equally in the North and South; (3) a distorted hyperbolic tangent density profile to produce the interior meridional density gradient but with no contribution to the surface meridional density gradient (equal contribution to the northern and southern surface profiles); this function also provides a stratification asymmetry between the lower and upper thermocline; (4) a hyperbolic tangent density profile for the southern profile only that has its inflection point close to the surface and is the only responsible for surface meridional density gradients.

The water within $200 \mathrm{~km}$ from the northern (resp. southern) boundary is homogeneous and has its density equal to the dense (resp., light) profile. In the center of the channel, density goes smoothly from light to dense over a length scale $\mathrm{L}_{j e t}=1600 \mathrm{~km}$ with the frontal zone being concentrated in $\mathrm{a} \sim 1000 \mathrm{~km}$ wide central region. 


$$
\begin{array}{r}
\rho_{N, S}(z)=\rho^{\max }-S_{b}\left(z+h_{\max }\right)-\frac{1}{2} \delta \rho_{N, S}^{\text {int }}\left[1+\tanh \left(\frac{d_{N, S}(z)-z_{N, S}^{\text {int }}}{\delta z_{N, S}}\right)\right] \\
-\frac{1}{2 \tanh (1)} \delta \rho_{N, S}^{\operatorname{surf}}\left[1+\tanh \left(\frac{z^{\text {surf }}-z}{z^{\text {surf }}}\right)\right]
\end{array}
$$

where,

$$
d_{N, S}(z)=z_{N, S}^{i n t}+\left(z-z_{N, S}^{i n t}\right)\left[1+0.5\left(\frac{z-z_{N, S}^{i n t}+\left|z-z_{N, S}^{i n t}\right|}{1.3 \delta z_{N, S}}\right)^{2}\right]^{0.5}
$$

$$
\delta \rho_{N}^{i n t}=\delta \rho_{S}^{i n t}\left[1+\tanh \left(\frac{d_{S}(0)-z_{S}^{i n t}}{\delta z_{S}}\right)\right] /\left[1+\tanh \left(\frac{d_{N}(0)-z_{N}^{i n t}}{\delta z_{N}}\right)\right],
$$

$z$ denotes depth, $h_{\text {max }}$ is the ocean depth $(4000 \mathrm{~m}), \rho_{\max }=27.75 \mathrm{~kg} \mathrm{~m}^{-3}, S_{b}=9.810^{-6} \mathrm{~kg} \mathrm{~m}^{-4}, \delta \rho_{N / S}^{i n t}=$ $1.41 / 1.4$ (the $\delta \rho_{N}^{\text {int }}$ value in bold is computed with Eq. 2 so that the first hyperbolic tangent term does not contribute to the surface meridional density difference), $z_{N / S}^{\text {int }}=-400 /-1000, \delta z_{N, S}=300 / 700, \delta \rho_{N, S}^{\text {surf }}=0 / 1.5$, $z^{\text {surf }}=-300$.

\section{Acknowledgements}

The authors thank the two anonymous reviewers who contributed to significantly improve this paper. This work and the first author were supported by the ANR project COMODO (ANR-11-MONU-005). Claude Talandier and Anne Marie Treguier were supported by CNRS, Aurelien Ponte, Franck Dumas and Valérie Garnier were supported by Ifremer. Simulations were performed on the CAPARMOR computing center at Ifremer.

\section{References}

Boccaletti, G.,Ferrari, R., Fox-Kemper, B., 2007. Mixed Layer Instabilities and Restratification. Journal of Physical Oceanogaphy $37,2228-2250$.

de Boyer Montégut, C.B., Madec, G., Fischer, A.S., Lazar, A., Iudicone, D., 2004. Mixed layer depth over the global ocean: an examination of profile data and a profile-based climatology. Journal of Geophysical Researsh 109.

Brannigan, L., Marshall, D.P., A. Naveira-Garabato, A.N., 2015. The seasonal cycle of submesoscale flows. Ocean Modelling 92, 69-84. 
Callies, J., Ferrari, R., Klymak, J.M., Gula, J., 2015. Seasonality in submesoscale turbulence. Nature Communication 6, 6862.

Capet, X., Campos, E.J., Paiva, A.M., 2008d. Submesoscale activity over the Argentinian shelf. Geophysical Research Letters 35.

Capet, X., McWilliams, J.C., Molemaker, M.J., Shchepetkin, A.F., 2008a. Mesoscale to Submesoscale Transition in the California Current System. Part I: Flow structure, Eddy Flux, and Observational Tests. Journal of Physical Oceanogaphy 38.

Capet, X., McWilliams, J.C., Molemaker, M.J., Shchepetkin, A.F., 2008b. Mesoscale to Submesoscale Transition in the California Current System. Part II: Frontal Processes. Journal of Physical Oceanography 38, 44-64.

Capet, X., McWilliams, J.C., Molemaker, M.J., Shchepetkin, A.F., 2008c. Mesoscale to Submesoscale Transition in the California Current System. Part III: Energy Balance and flux. Journal of Physical Oceanography, 2256-2269.

Fox-Kemper, B., Danabasoglu, G., Ferrari, R., Griffies, S.M., Hallberg, R., Holland, M.M., Maltrud, M.E., Peacock, S., Samuels, B.L., 2011. Parameterization of mixed layer eddies. III: Implementation and impact in global ocean climate simulations. Ocean Modelling 39, 61-78.

Fox-Kemper, B., Ferrari, R., 2008. Parameterization of Mixed Layer Eddies. Part II: Prognosis and Impact. Journal of Physical Oceanography 38, 1166-1179.

Fox-Kemper, B., Ferrari, R., Hallberg, R., 2008. Parameterization of Mixed Layer Eddies. Part I: Theory and Diagnosis. Journal of Physical Oceanogaphy 38, 1145-1165.

Haine, T.W.N., Marshall, J., 1998. Gravitational, Symmetric, and Baroclinic Instability of the Ocean Mixed Layer. Journal of Physical Oceanography 28, 634-658.

Hamlington, P.E., Roekel, L.P.V., Fox-Kemper, B., Julien, K., Chini, G.P., 2014. Langmuir-Submesoscale Interactions: descriptive Analysis of Multiscale Frontal Spindown Simulations. Journal of Physical Oceanography 44, $2250-2272$.

Haney, S., Bachman, S., Cooper, B., Kupper, S., McCaffrey, K., Roekel, L.V., Stevenson, S., Fox-Kemper, B., Ferrari, R., 2012. Hurricane wake restratification rates of one-, two- and three-dimentional processes. Journal of Marine Research 70, 824-850.

Klein, P., Hua, B.L., Lapeyre, G., Capet, X., Gentil, S.L., Sasaki, H., 2008. Upper Ocean Turbulence from High-Resolution 3D Simulation. Journal of Physical Oceanography 38, 1748-1763.

Klein, P., Lapeyre, G., 2009. The Oceanic Vertical Pump Induced by Mesoscale and Submesoscale Turbulence. Annu. Rev. Marine. Sci. , 351-375.

Klein, P., Lapeyre, G., Roullet, G., Gentil, S.L., Sasaki, H., 2011. Ocean turbulence at meso ansd submesoscales: connection between surface and interior dynamics. Geophysical \& Astrophysical Fluid Dynamics 105, 421-437.

Lavender, K.L., Davis, R.E., 2002. Observations of Open-Ocean Deep Convection in the Labrador Sea from Subsurface Floats. Journal of Physical Oceanography 32, 511-526.

Legg, S., McWilliams, J.C., Gao, J., 1998. Localization of Deep Ocean Convection by a Mesoscale Eddy. Journal of Physical Oceanography 28, 944-970.

Lemarie, F., Debreu, L., Madec, G., Demange, J., Molines, J.M., Honnorat, M., 2015. Stability constraints for oceanic numerical models: implications for the formulation of time and space discretizations. Ocean Modelling 92, 124-148.

Lévy, M., Klein, P., Tréguier, A.M., Lovino, D., Madec, G., Masson, S., Takahashi, K., 2010. Modifications of gyre circulation by sub-mesoscale physics. Ocean Modelling 34, 1-15. 
Lévy, M., Resplandy, L., Klein, P., Capet, X., Lovino, D., Ethé, C., 2012. mesoscale resolving ocean models: Benefits for offline passive tracer transport. Ocean Modelling 48, 1-9.

Lin, I.I., Chen, C.H., Pun, I.F., Liu, W.T., Wu, C.C., 2009. Warm ocean anomaly, air sea fluxes, and the rapid intensification of tropical cyclone Nargis (2008). Geophysical Research Letters 36.

Liu, C., Wang, Z., 2014. On the response of the global subduction rate to globalwarming in coupled climate models. Advances in Atmospheric Sciences 31, 211-218.

Madec, G., 2008. NEMO ocean engine. Note du Pole de modelisation de 1'Institut Pierre-Simon Laplace No 27, ISSN No 12881619. .

Mahadevan, A., D’Asaro, E., Lee, C., Perry, M.J., 2012. Eddy-Driven Stratification Initiates North Atlantic Spring Phytoplankton blooms. Science 337.

Marchesiello, P., Capet, X., Menkes, C., Kennan, S.C., 2011. Submesoscale dynamics in tropical instabilit waves. Ocean Modelling $39,31-46$.

Marchesiello, P., Debreu, L., Couvelard, X., 2009. Spurious diapycnal mixing in terrain-following coordinate models: The problem and a solution. Ocean Modelling 26, 156-169.

McWilliams, J.C., Chow, J.H.S., 1981. Equilibrium geostrophic turbulence: I. A reference solution in a beta-plane channel. Journal of Physical Oceanography 11, 921-949.

Mensa, J.A., Garraffo, Z., Griffa, A., Ozgokmen, T.M., Hasa, A., Veneziani, M., 2013. Seasonality of the submesoscale dynamics in the Gulf Stream region. Ocean Dynamics 63, 923-941.

Mohammadi-Aragh, M., Klingbeil, K., Bruggemann, N., Eden, C., Burchard, H., 2015. The impact of advection schemes on lateral shear and baroclinic instability. Ocean Dynamics 94, 112-127.

Munk, W., Armi, L., Fisher, K., Zachariansen, F., 2000. Spirals on the sea. Proc. R. Soc. London. Ser. A 456, 1217-1280.

Nurser, A.J.G., Zhang, J.W., 2000. Eddy-induced mixed layer shallowing and mixed layer/thermocline exchange. Journal of Geophysical Research 105, 21,851-21,868.

Ponte, A.L., Klein, P., Capet, X., Traon, P.Y.L., Chapron, B., Lherminier, P., 2013. Diagnosing Surface Mixed Layer Dynamics from High-Resolution Satellite Observations: Numerical Insights. Journal of Physical Oceanography 43, 1345-1355.

Ramachandran, S., Tandon, A., Mahadevan, A., 2014. Enhancement in vertical fluxes at a front by mesoscale-submesoscale coupling. Journal of Geophysical Research: Oceans 119, 8495-8511.

Romanou, A., Gregg, W., Romanski, J., Kelley, M., Bleck, R., Healy, R., Nazarenko, L., Russell, G., Scmidt, G.A., Sun, S., Tausney, ., 2013. Natural air-sea flux of CO2 in simulations of the NASA-GISS climate model: Sensitivity to the physical ocean model formulation. Ocean Modelling 66, 26-44.

Rosso, I., Hogg, A.M., Strutton, P.G., Kiss, A.E., Matear, R., Klocker, A., van Sebille, E., 2014. Vertical transport in the ocean due to sub-mesoscale structures: Impacts in the Kerguelen region. Ocean Modelling 80, 10-23.

Roullet, G., Madec, G., 2000. Salt conservation, free surface, and varying levels: a new formulation for ocean general circulation models. J. Geophys. Res. 105, 927-942.

Sallee, J.B., Shuckburgh, E., Bruneau, N., Meijers, A.J..S., Bracegirdle, T.J., Wang, Z., 2013. Assessment of Southern Ocean 
mixed-layer depths in CMIP5 models: Historical bias and forcing response. Journal of Geophysical Research-Oceans 118, $1845-1862$.

Sasaki, H., Klein, P., Qiu, B., 2014. Impact of oceanic-scale interactions on the seasonal modulation of ocean dynamics by the atmosphere. Nature Communication .

Scully-Power, P., 1986. Navy Oceanographer Shuttle Observations, STS 41-G, Mission Report. Naval Underwater Systems Center Tech. Rep. NUSC TD 7611, 71pp.

Seo, H., Xie, S., 2013. Impact of ocean warm layer thickness on the intensity of hurricane Katrina in a regional coupled model. Meteorology And Atmospheric Physics 122, 19-32.

Shay, L.K., Brewster, J.K., 2010. Oceanic Heat Content Variability in the Eastern Pacific Ocean for Hurricane Intensity Forecasting. Monthly Weather Review 138, 2110-2131.

Skyllingstad, E.D., Samelson, R.M., 2012. Baroclinic Frontal Instabilities and Turbulent Mixing in the Surface Boundary Layer. Part I: Unforced Simulations. Journal of Physical Oceanography 42, 1701-1716.

Soufflet, Y., Marchesiello, P., Jouano, J., Capet, X., Debreu, L., Lemarie, F., 2015. On effectiye resolution in ocean models. Ocean Modelling (submitted).

Straneo, F., 2005. Heat and Freshwater Transport through the Central Labrador Sea. Journal of Physical Oceanography 36, $606-628$.

Swart, S., Thomalla, S.J., Monteiro, P.M.S., 2014. The seasonal cycle of mixed layer dynamics and phytoplankton biomass in the Sub-Antarctic Zone: a high-resolution glider experiment. Journal of Marine Systems 147, 103-115.

Taylor, J.R., Ferrari, R., 2010. Buoyancy and Wind-Driven Convection at Mixed Layer Density Fronts. Journal of Physical Oceanography 40, 1222-1242.

Taylor, J.R., Ferrari, R., 2011. Ocean fronts trigger high latitude phytoplankton blooms. Geophys. Res. Let. 38.

Thomas, L.N., Tandon, A., Mahadevan, A., 2013. Submesoscale Processes and Dynamics. Ocean Modeling in a eddying regime (eds M. W. Hecht and H. Hasumi), American Geophysical Union, Washington, D. C. ) . 


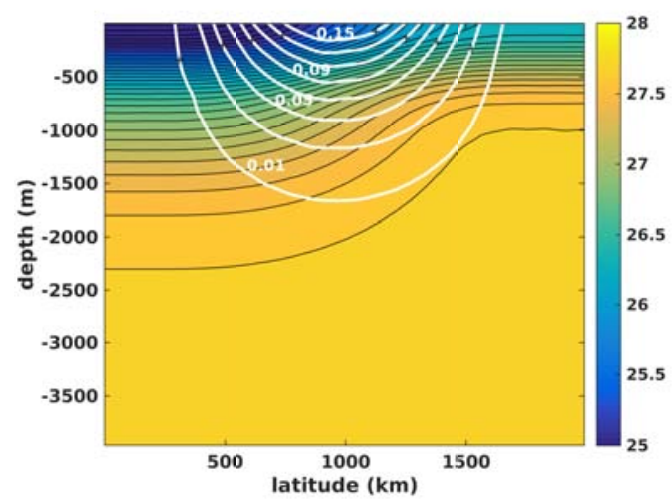

(a)

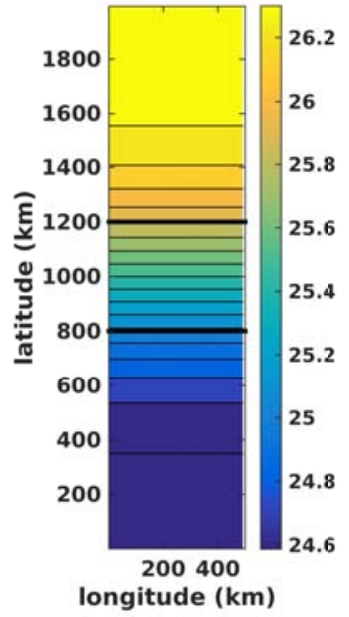

(b)

Figure 1: (a) Meridional section of the initial density anomaly $\left(\mathrm{kg} \cdot \mathrm{m}^{-3}\right)$, with north on the right. White contour represents the corresponding zonal velocity (contour spacing is $2 \mathrm{~cm} . \mathrm{s}^{-1}$ ) (b) initial surface density anomaly. The thick dark lines represent the meridional extent of the box considered in the analysis.

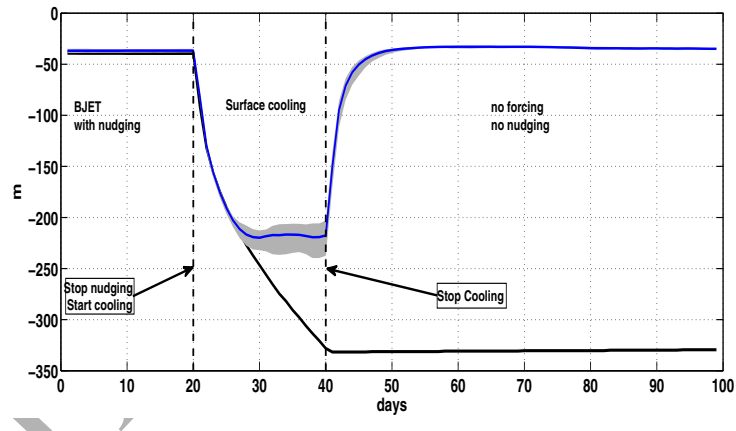

Figure 2: Schematic view of the cooling event. The blue line represents the horizontally-averaged (over the box delimited in Figure 1b) mixed layer depth for the $2 \mathrm{~km}$ simulation averaged over all the members. The gray patch represents the spread over the ensemble. The dark line represents the horizontally-averaged (over the same domain) mixed layer depth in the absence of turbulence. Vertical dotted lines represent the beginning and the end of the cooling period.The mixed layer before the onset of the cooling is not an actual mixed layer but an arbitrary depth picked up by the density criterion. 


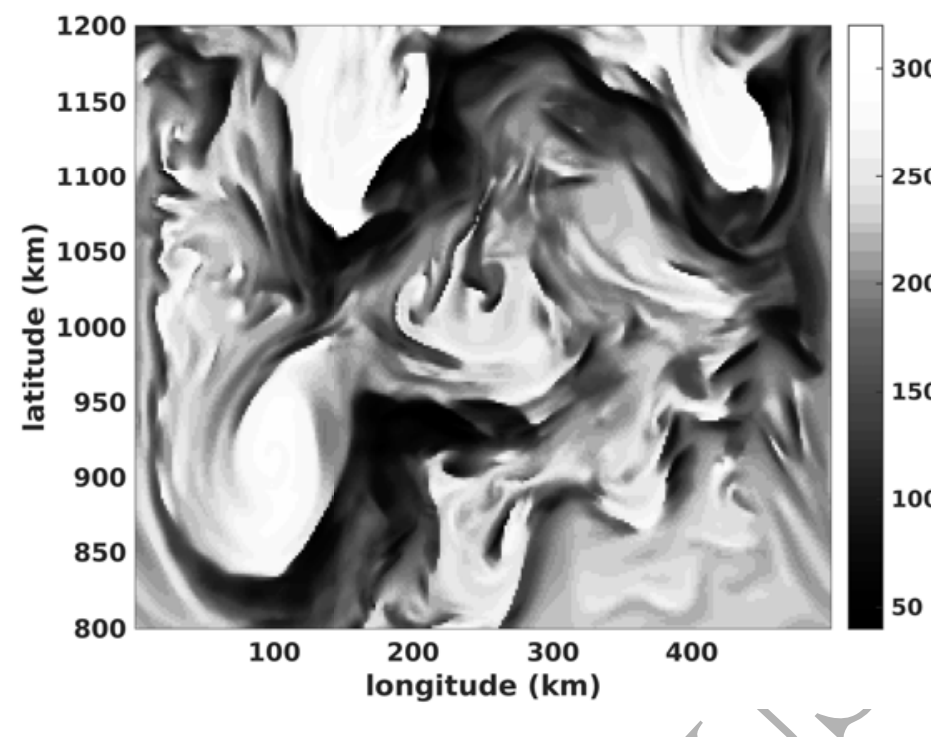

Figure 3: Mixed Layer Depth (in meters) in the middle box after 10 days of cooling.

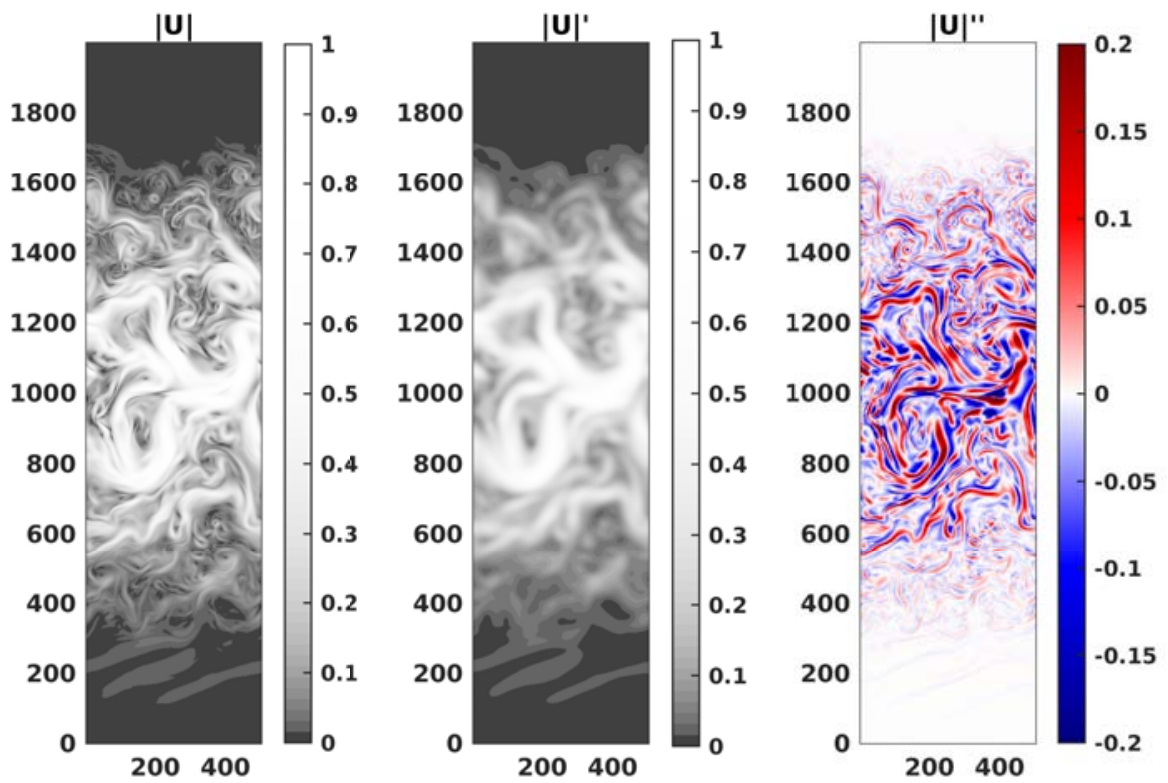

Figure 4: Before cooling daily-averaged surface velocities $\left(\mathrm{m} . \mathrm{s}^{-1}\right)$ : full velocity (left panel), filtered velocity, i.e., large + mesoscale (middle panel) and residual, i.e., submesoscale (right panel). 


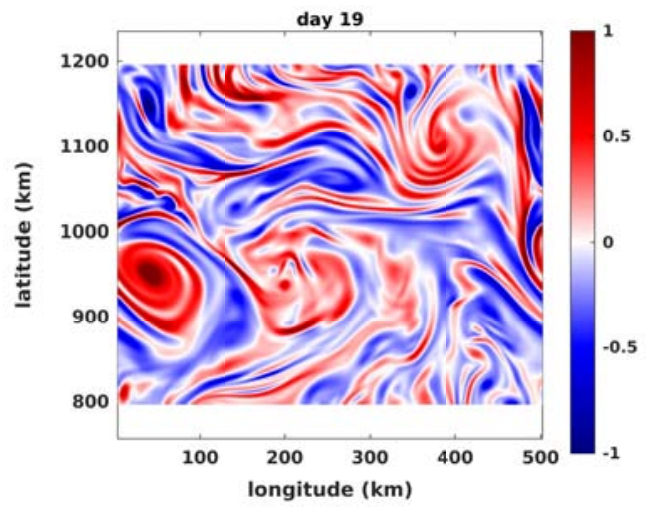

(a)

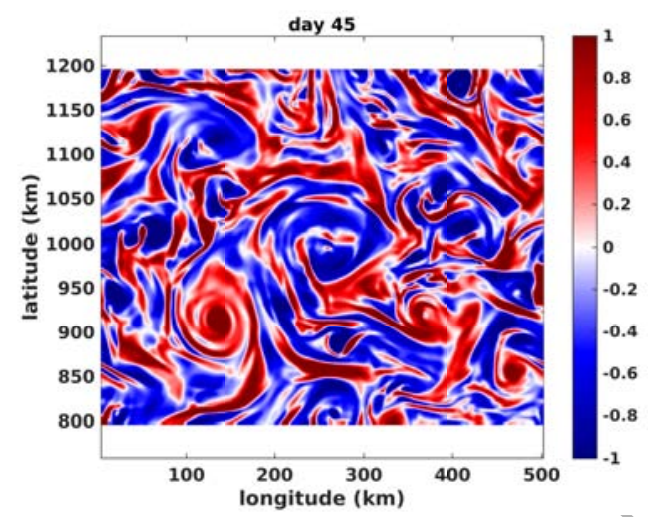

(c)

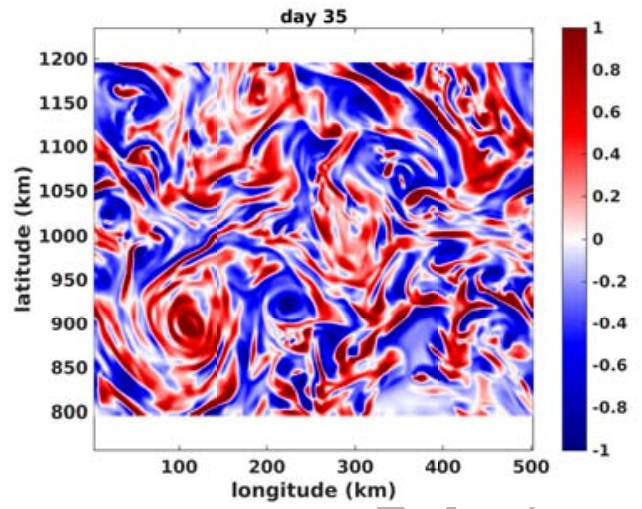

(b)

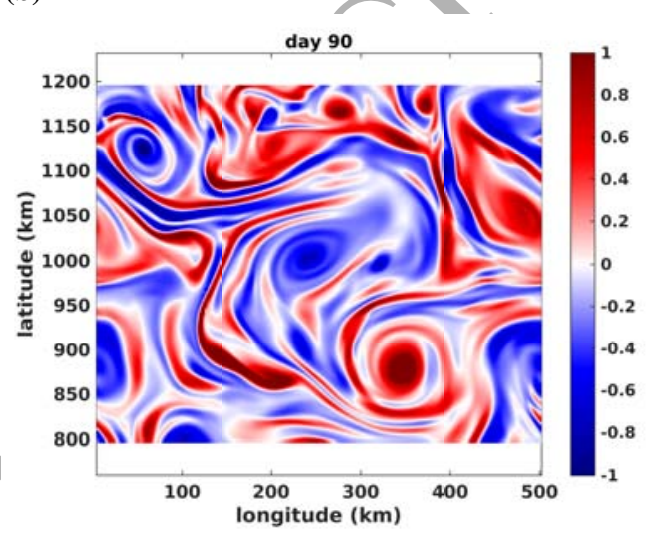

(d)

Figure 5: Mean daily surface $\zeta$ (relative to f): (a) before the mixed layer formation (day 19), (b) during the mixed layer formation (day 35), (c) during the restratification (day 45) and (d) after the restratification (day 90).

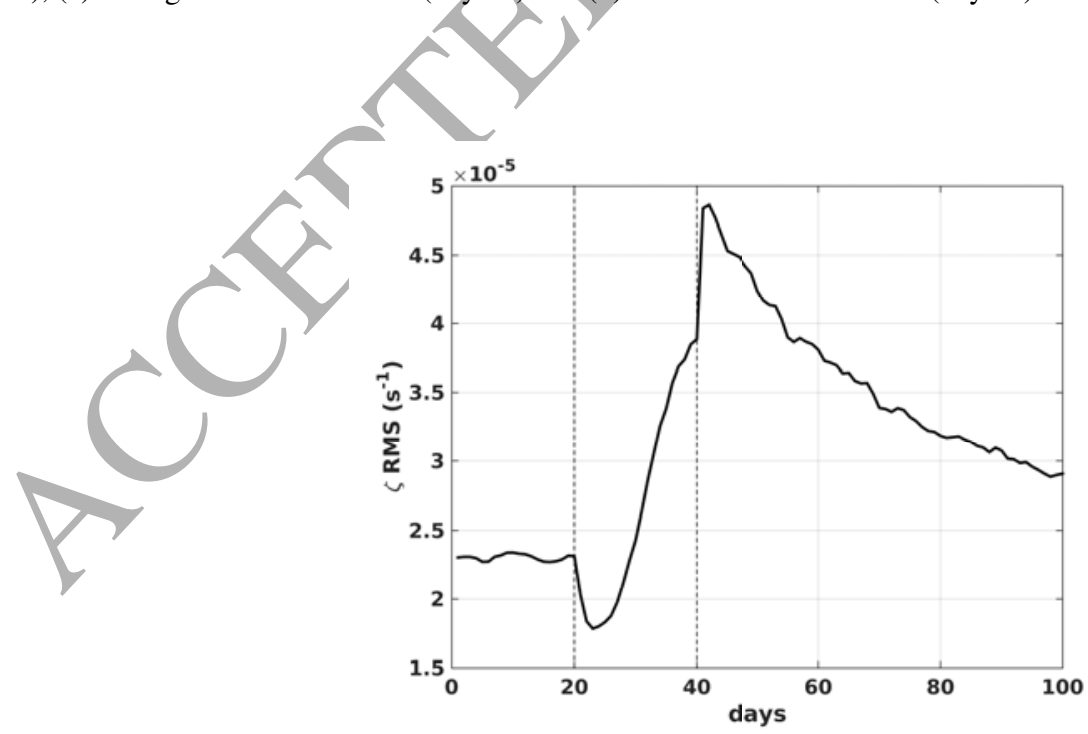

Figure 6: RMS $\zeta$ spatially averaged over the middle box. Vertical dotted line at days 20 and 40 delimits the cooling period. 


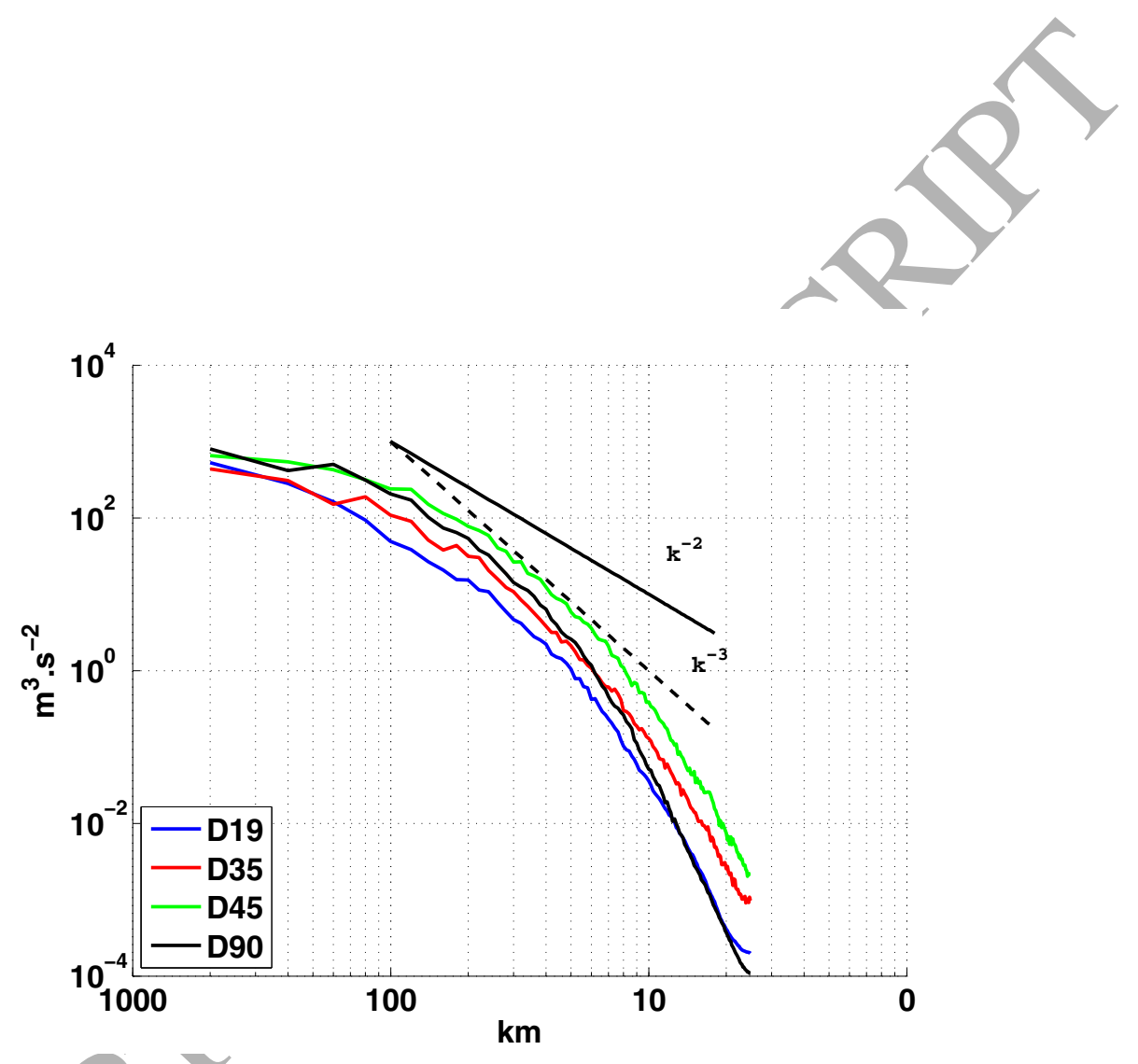

Figure 7: Surface kinetic energy spectrum (averaged over the ensemble) corresponding to the days of the snapshots of Figure 5. blue: day 19, red: day 35, green: day 45, dark: day 90. Dotted and plain dark lines represent the $k^{-3}$ and $k^{-2}$ slopes.

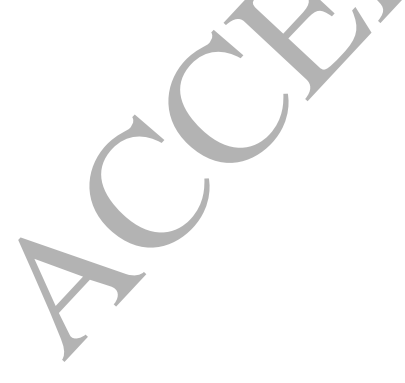



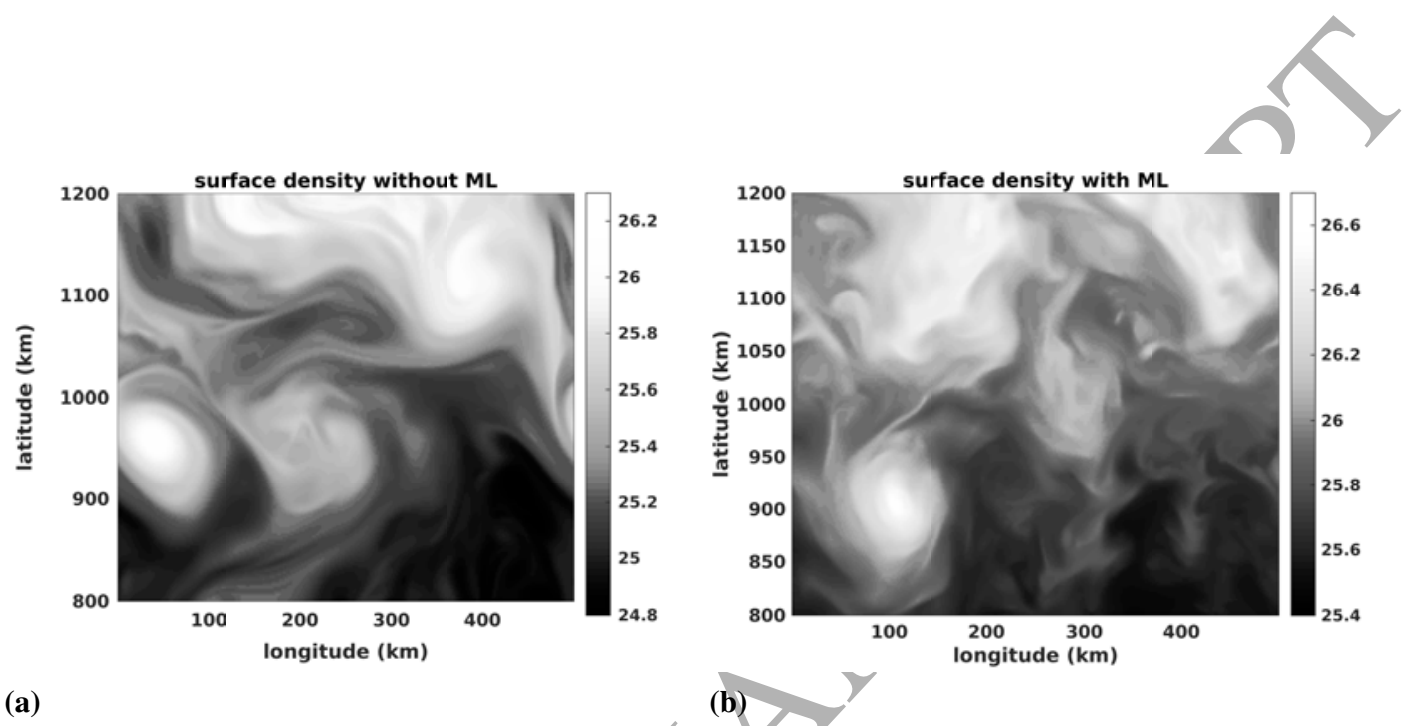

(a)

(b)
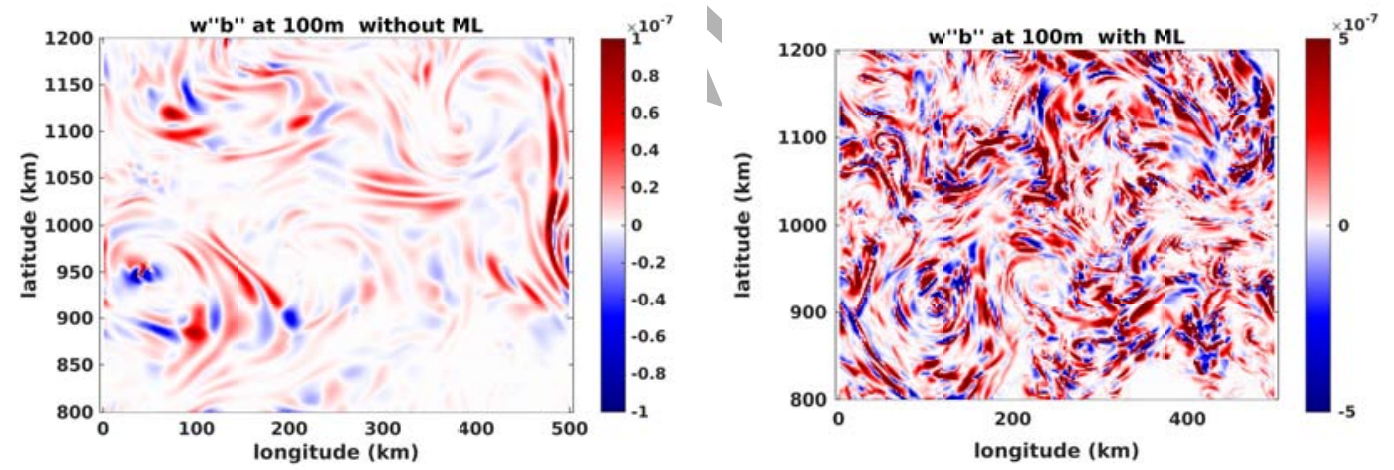

(c)

(d)

Figure 8: Surface density anomaly $\left(\mathrm{kg} \cdot \mathrm{m}^{-3}\right.$ ) before (day 19) and during (day 35) the mixed layer formation, panel (a) and (b) respectively. Corresponding submesoscale upward buoyancy flux at $100 \mathrm{~m}\left(\mathrm{~m}^{2} \mathrm{~s}^{-3}\right)$, (c): day 19 and (d): day 35 . 

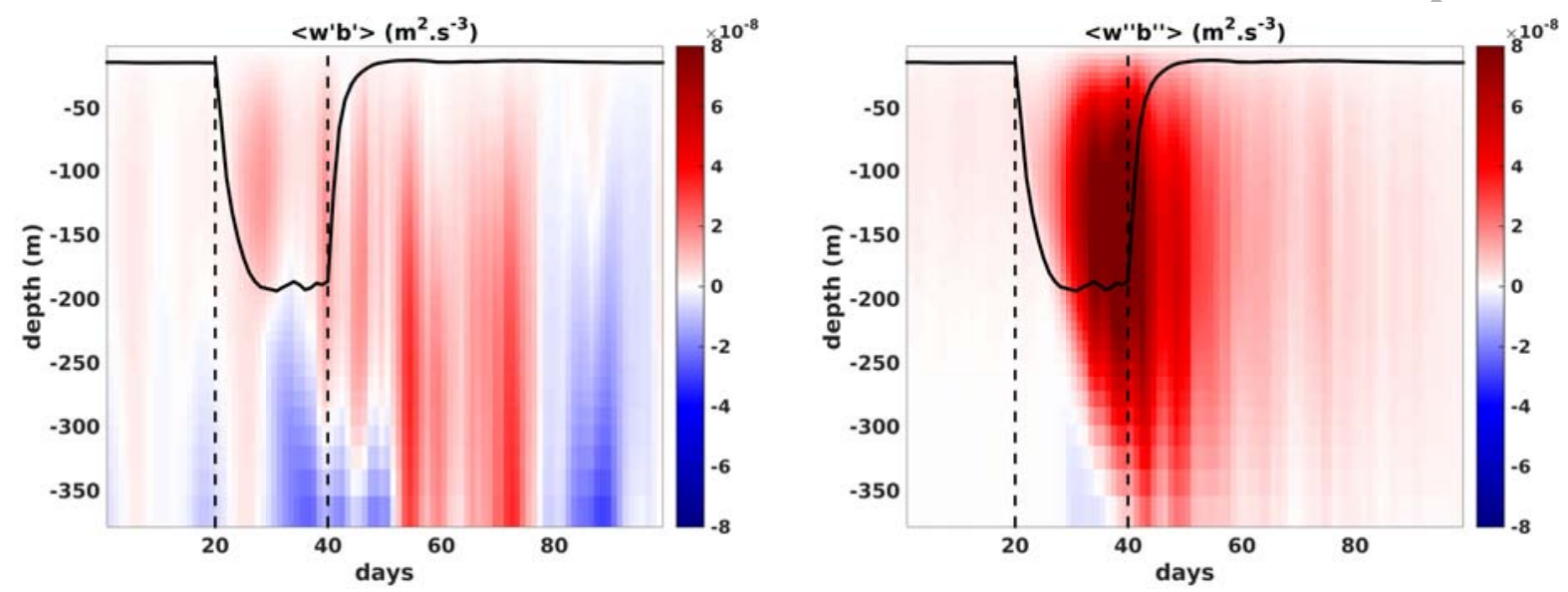

(a)

(b)

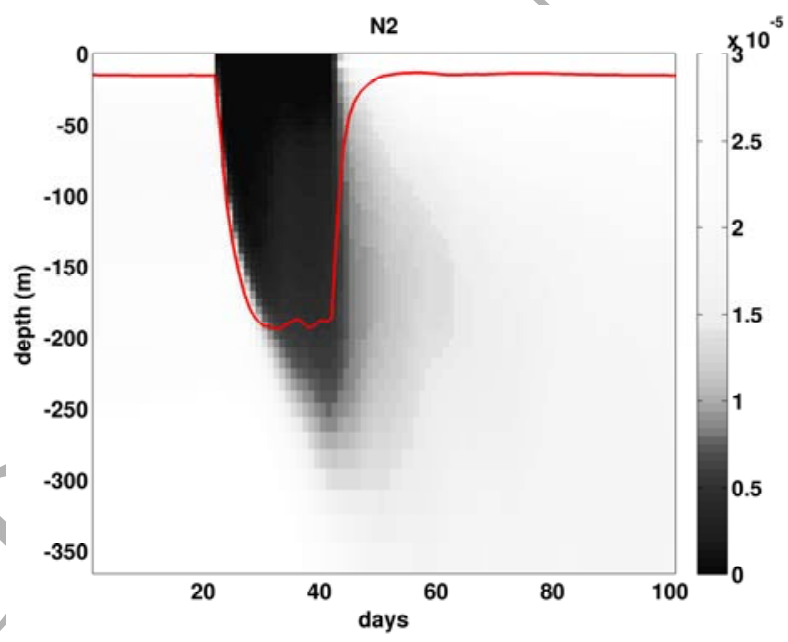

(c)

Figure 9: (a) depth-time section of the spatially-averaged large scale buoyancy flux. (b) depth-time section of the spatially-averaged submesoscale buoyancy flux. The black line represents the spatially-averaged MLD and the vertical dotted line represents the beginning (day 20) and the end (day 40) of the cooling period. (c) depth-time section of the spatially-averaged $\mathrm{N}^{2}$, the red line represents the spatially-averaged MLD. The horizontal axis represents the 100 days of a cooling event (cf 2.3). 


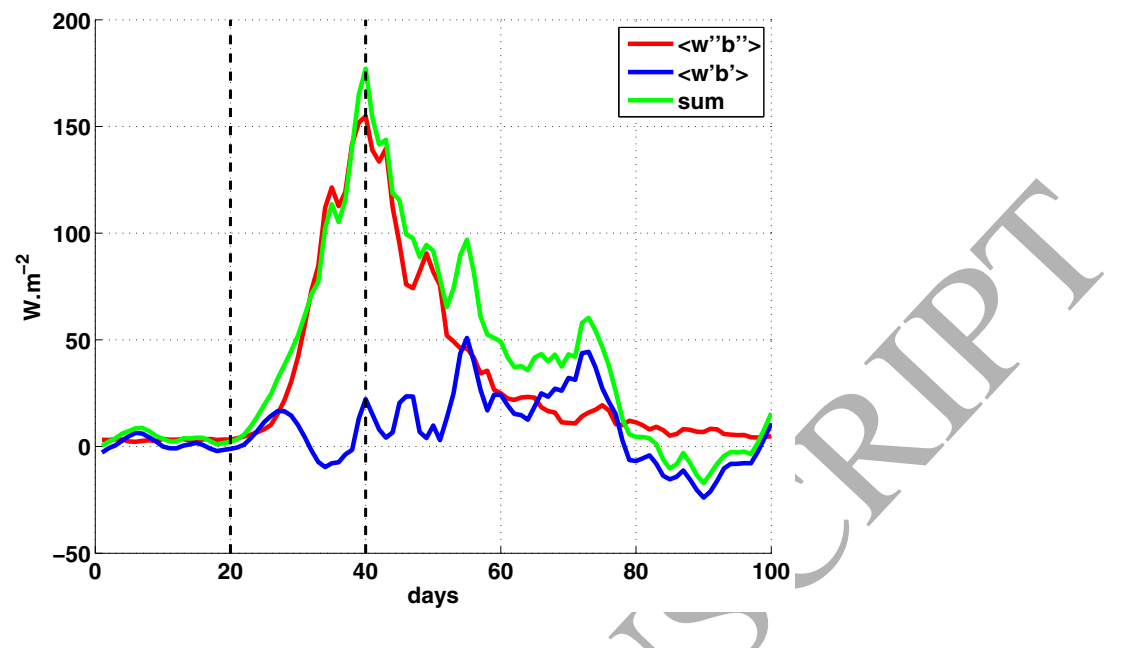

Figure 10: Vertically- (0-350 m)averaged vertical buoyancy flux corresponding to Figure 9, converted in equivalent heat flux. The green line is the total flux, the red line the submesoscale flux, and the blue line the difference between the two (large scale and mesoscale flux component). The vertical dotted line delimits the cooling period.

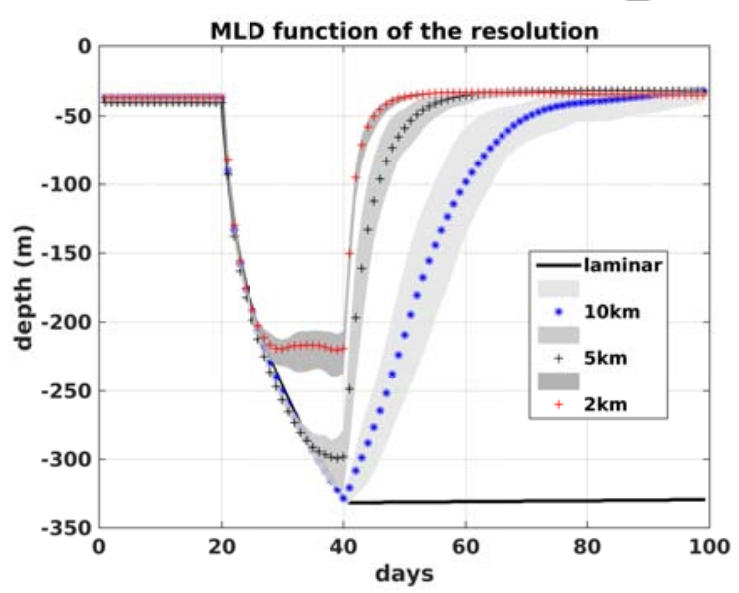

(a)

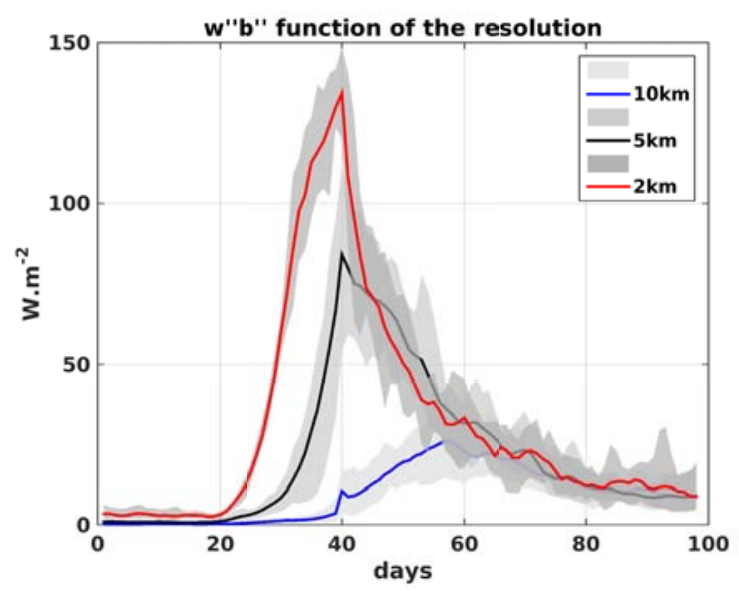

(b)

Figure 11: (a) Spatially averaged Mixed Layer Depth as a function of time for the different resolutions. Solid lines: without turbulence; symbols: fully turbulent jet.(b) vertically-averaged (0-350 m) submesoscale buoyancy flux for the different resolutions. For both panels, $2 \mathrm{~km}$ resolution is given in red, $5 \mathrm{~km}$ in black and $10 \mathrm{~km}$ in blue. The shaded areas represent the spread over each ensemble. 


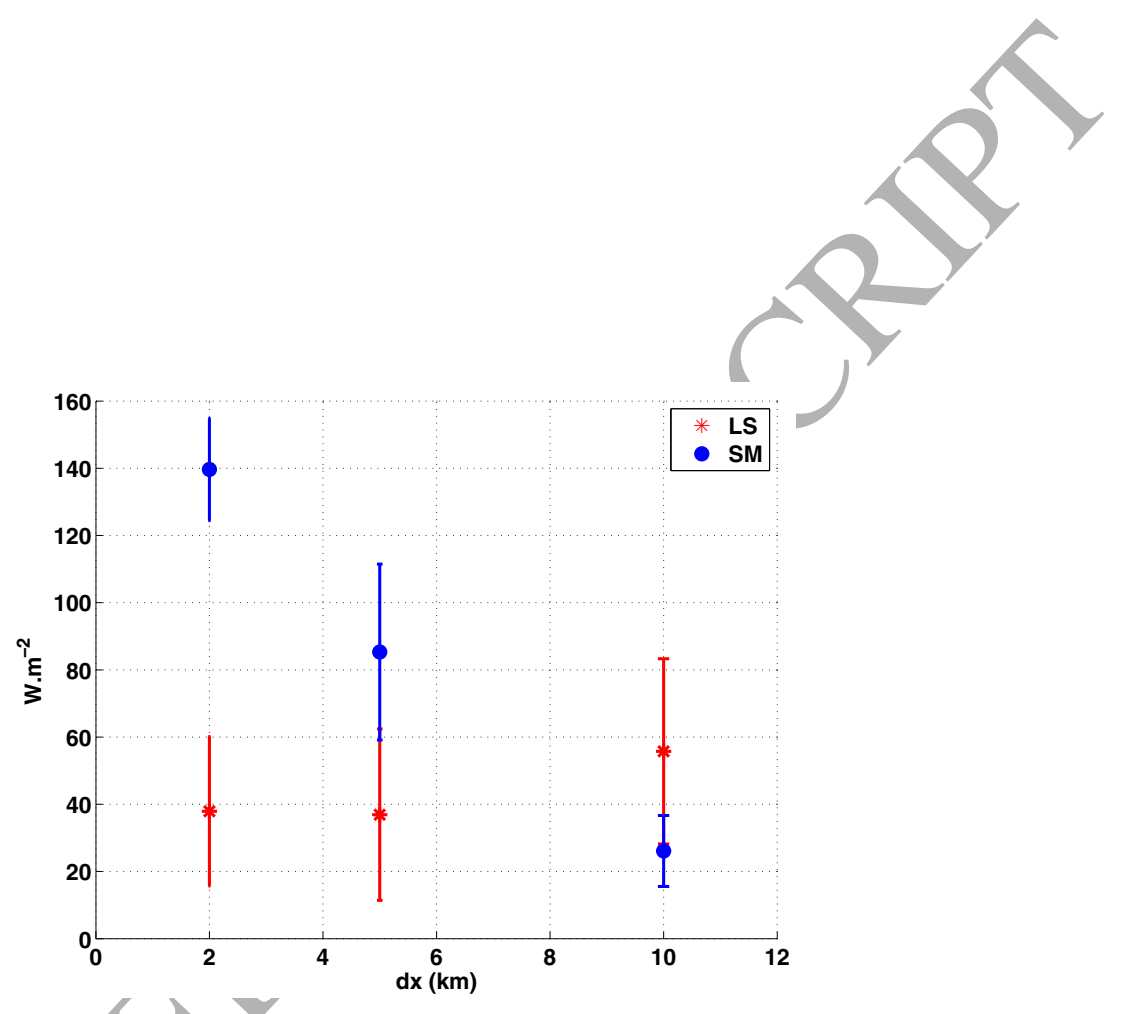

Figure 12: Maximum value of the two components of $\left\langle w^{\prime} b^{\prime}\right\rangle$ as a function of the model resolution (red: large and mesoscale; blue: submesoscale). The ensemble mean is represented by a point and the vertical bars show the uncertainties as deduced from the ensemble. While the large scale (LS) component tends to be constant among the different resolutions, the submesoscale (SM) component increases almost linearly with the decrease of the grid scale.

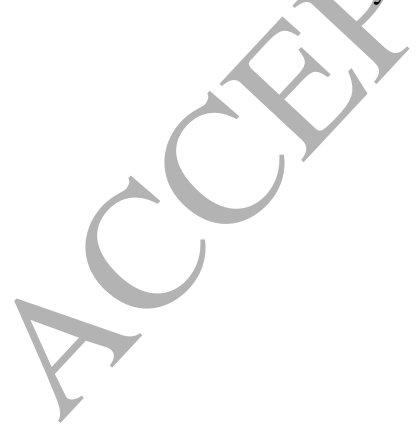



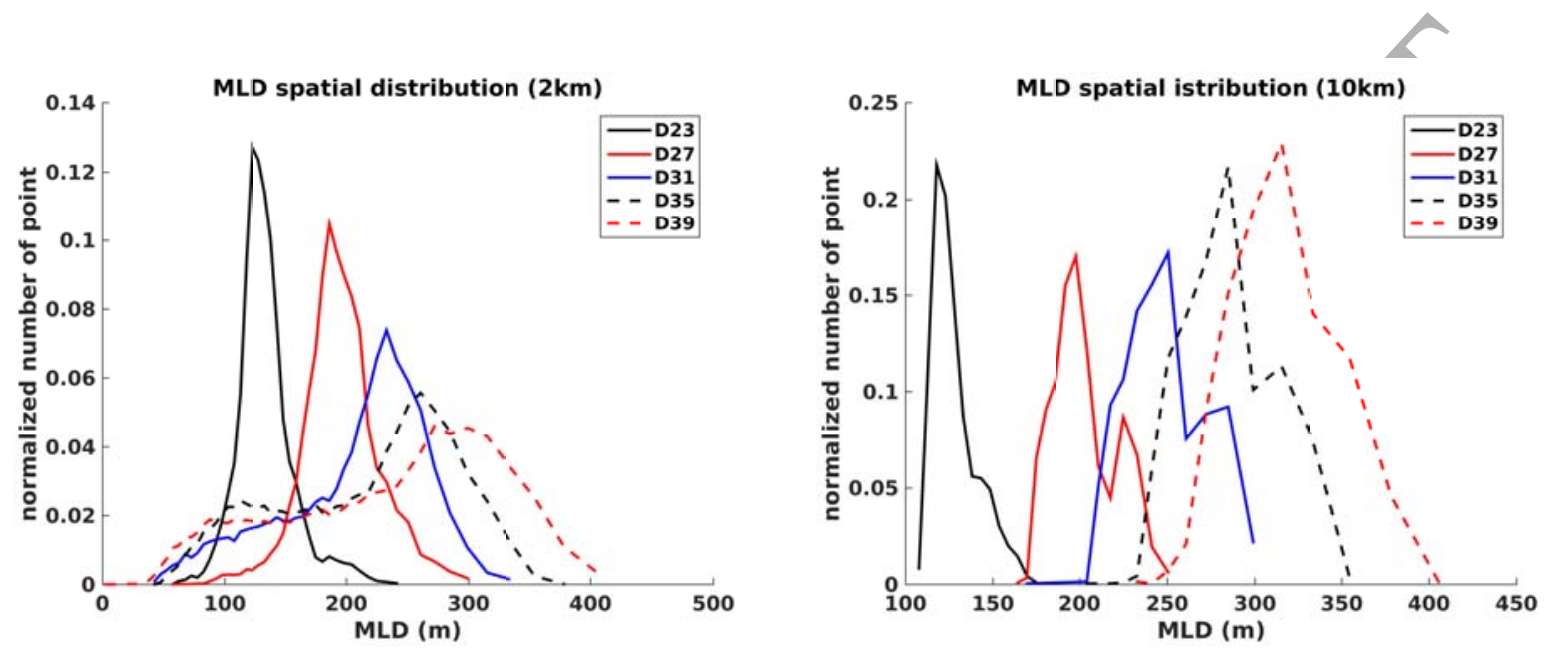

(a)

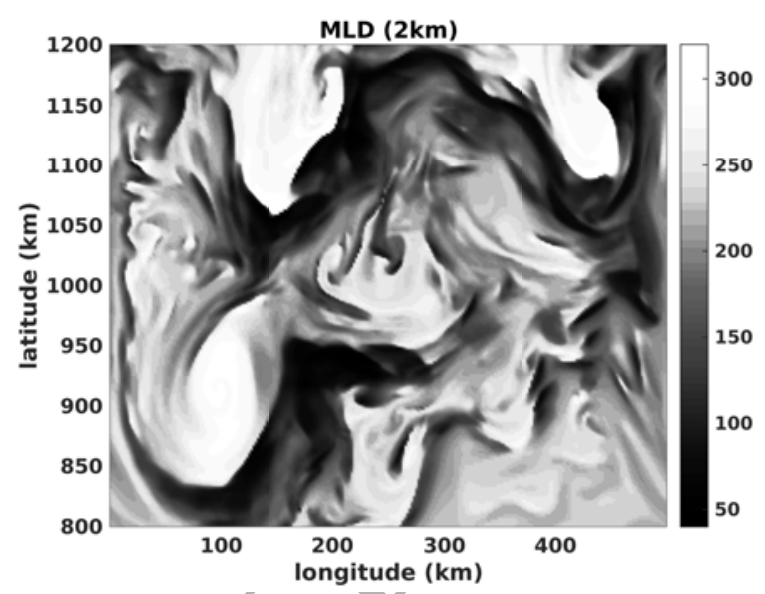

(b)

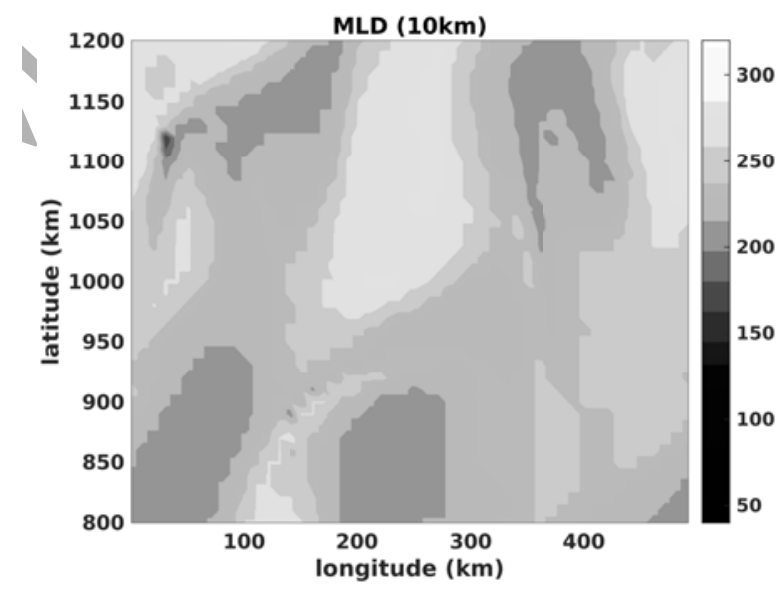

(c)

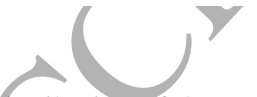

(d)

Figure 13: Distribution of the number of grid points (normalized by the total) as a function of MLD for the central domain. Each curve represents a different day from day 23 to day 39. (a)- km,(b)-10 km. (c) and (d) represent snapshots of the MLD (in meters) after 10 days of cooling at 2 and $10 \mathrm{~km}$ respectively. 